Geopolítica(s) Revista de estudios sobre espacio y poder

ISSN: 2172-3958

\title{
Comentario. La innovación de Perón en 1953: fundamentos históricos para una geopolítica crítica en Sudamérica ${ }^{1}$
}

\author{
Julio Burdman ${ }^{2}$
}

Recibido: 1 de junio de 2020 / Aceptado: 12 de junio de 2020

Resumen. El discurso de Perón del 11 de noviembre de 1953 es un parteaguas de al menos dos historias: la del peronismo en Argentina, y la del pensamiento geopolítico en Sudamérica. El entonces presidente argentino, que también ejercía el rol de ideólogo principal del movimiento político que lideraba, explica aquí las razones de su proyecto de integración regional, el $A B C$ sudamericano. Expone su versión sobre las causas del fracaso, y propone un cambio de estrategia, que es la apelación al pueblo. En ese momento, se produce un cambio en su visión geopolítica: convoca a una ruptura con las categorías y conceptos del pasado, y a la adopción de una (geo)estrategia nacional-popular para la consecución de transformaciones geográficas y sociales. Este cambio ha sido analizado en clave histórica, considerando al contexto particular de la Guerra Fría que afectaba a los gobiernos sudamericanos, pero también se ha construido alrededor de él una teoría del regionalismo sudamericano. Sobre esta segunda dimensión, argumentaremos que la innovación de Perón no fue la decisión de practicar una geopolítica clásica (ratzeliana) desde el Sur, como sostuvieron Methol Ferré y sus discípulos, sino su giro hacia lo que hoy entendemos como geopolítica crítica: además de disentir con el orden hegemónico, descubre la "trampa territorial", el fin de la geopolítica convencional y los límites de la política exterior de los Estados-nación.

Palabras clave: Juan Domingo Perón; integración sudamericana; geopolítica crítica; continentalismo; tercera posición.

\section{[en] Commentary. Perón's Innovation in 1953: Historical Foundations for Critical Geopolitics in South America}

\footnotetext{
Abstract. Perón's speech on November 11, 1953 is a watershed for at least two historical paths: that of Peronism in Argentina, and that of geopolitical thought in South America. The then Argentine president, who also played the role of the main ideologue of the political movement he led, explains the reasons for his regional integration project, the South American $A B C$, exposes his viewpoint on the causes of its failure, and proposes a change in strategy, which is the appeal to the people. At that moment, a change occurs in his geopolitical vision: he calls for a break with categories and concepts from the past, and for the adoption of a national-popular (geo)strategy for achieving geographic and social transformations. This change has been analyzed historically, considering the Cold War context that affected South American governments, but also a theory of South American regionalism has been

1 (Nota de la redacción) Comentario sobre el texto de Juan Domingo Perón: "Unidos o Dominados". Discurso pronunciado el 11 de noviembre de 1953 en la Escuela Nacional de Guerra de Argentina. El autor agradece a Fabián Brown por sus comentarios y sugerencias.

2 Facultad de Ciencias Sociales, Universidad de Buenos Aires (Argentina).

E-mail: julioburdman@derecho.uba.ar
} 
built around it. On this second dimension, we argue that Perón's innovation was not the decision to practice classical (ratzelian) geopolitics from the South, as Methol Ferré and his disciples argued, but his turn towards what we now understand as critical geopolitics: in addition to dissent with the hegemonic order, he discovers the "territorial trap", the end of conventional geopolitics and the limits of the foreign policy of nation-states.

Keywords: Juan Domingo Perón; South American integration; critical geopolitics; continentalism; third way.

\section{[pt] Comentário. A inovação de Perón em 1953: fundamentos históricos pa- ra uma geopolítica crítica na América do Sul}

Resumo. O discurso de Perón de 11 de novembro de 1953 é um divisor de águas para pelo menos duas histórias: a do peronismo na Argentina e a do pensamento geopolítico na América do Sul. O então presidente argentino, que também exerceu o papel de principal ideólogo do movimento político que liderou, explica aqui as razões de seu projeto de integração regional, o $A B C$ sul-americano. Ele expõe sua versão das causas do fracasso e propõe uma mudança de estratégia, que é o apelo ao povo. Nesse momento, ocorre uma mudança em sua visão geopolítica: ele pede uma ruptura com as categorias e conceitos do passado e a adoção de uma (geo)estratégia nacional-popular para obter transformações geográficas e sociais. Essa mudança foi analisada historicamente, considerando o contexto particular da Guerra Fria que afetou os governos sul-americanos, mas uma teoria do regionalismo sulamericano também foi construída em torno dela. Com relação a esta segunda dimensão, argumentaremos que a inovação de Perón não foi a decisão de praticar a geopolítica clássica (ratzeliana) do Sul, como argumentaram Methol Ferré e seus discípulos, mas sim a sua vez em relação ao que agora entendemos como geopolítica crítica: além de discordar da ordem hegemônica, ele descobre a "armadilha territorial", o fim da geopolítica convencional e os limites da política externa dos estados-nação.

Palavras-chave: Juan Domingo Perón; integração sul-americana; geopolítica crítica; continentalismo; terceira posição.

Sumario. Introducción: la encrucijada de Perón. 1. El código geopolítico peroniano. 2. Discusión: ¿código geopolítico argentino o nacionalismo latinoamericano? 3. Giro a una geopolítica alternativa: la (geo)estrategia nacional popular. Referencias.

Cómo citar: Burdman, J. (2020). "Comentario. La innovación de Perón en 1953: fundamentos históricos para una geopolítica crítica en Sudamérica". Geopolitica(s). Revista de estudios sobre espacio y poder, vol. 11, núm. 1, 185-200.

\section{Introducción: la encrucijada de Perón}

El discurso pronunciado por Juan Perón el 11 de noviembre de 1953 en la Escuela Nacional de Guerra es una pieza fundamental para entender las motivaciones y justificaciones de su práctica geopolítica. Perón fue presidente entre los años 1946 y 1955, aunque su gravitación en el gobierno argentino comienza en noviembre de 1943, cuando asume como secretario de Trabajo y Previsión del régimen nacionalista que había accedido al poder con el golpe de Estado del 4 de junio anterior. Esos doce años coincidieron con profundas transformaciones mundiales, y de las opciones internacionales del Estado argentino. Y ya como presidente, apoyado en un amplio respaldo popular, se atribuyó la misión de interpretar dichas transformaciones, impulsar las políticas argentinas para enfrentarlas, y comunicar su visión al público. La presidencia adquiere un nuevo tipo de función político-internacional: "cuando yo me hice cargo del gobierno, la política internacional argentina no tenía 
ninguna definición", advierte (Perón, 2020, p.177); ahora, las definiciones las provee el presidente.

En este nuevo género de visiones geopolíticas presidenciales, "Unidos o Dominados" es un discurso particularmente rico para poder interpretar al intérprete. Perón y Vargas se encuentran en una encrucijada; fueron derrotados, y lo que les espera será aún peor - Vargas se suicida pocos meses después y Perón, derrocado, partirá a un exilio de 18 años-. En un marco reservado, el presidente argentino explica qué quiso hacer y por qué falló. Su proyecto de unión económica sudamericana (el $A B C$ entre Argentina, Brasil y Chile; se esperaba que el resto de los países se incorporasen después) fue frenado por la cancillería brasileña, sin que los presidentes pudiesen evitarlo. Pero, en medio del revés, Perón actualiza su concepto: más que Itamaraty, el problema fue que el pueblo (brasileño) no estaba listo. Porque las geografías ya no las cambian los gobiernos, sino los pueblos.

Quien pronuncia el discurso, Juan Perón, está ejerciendo un doble rol: es el líder político del peronismo $-\mathrm{y}$, circunstancialmente, el presidente argentino-, y también es su ideólogo principal. Al encarnar la visión geopolítica, es quien escribe su doctrina. Eso nos plantea un desafío acerca de la frontera porosa que separa a los discursos geopolíticos formales de los prácticos, de acuerdo con la definición de Ó Tuathail (1996). En nuestra era de profesionalización académica, caracterizada por altos grados de separación entre ciencias sociales y política práctica - que reconocidos académicos estadounidenses como Joseph Nye o Robert Putnam ya consideran excesiva ${ }^{3}$ - , Perón no sería considerado como un productor de conocimiento formal. Pero su tiempo era otro. Nacido en 1895, el universo de sentido del General eran los políticos militares que ocupaban los más altos cargos ejecutivos y ejercían desde ahí la función de intelectuales de Estado. Algunos de los constructores de la nación argentina de la segunda mitad del siglo XIX, como Mitre o Sarmiento, fueron militares, líderes partidarios, presidentes y también autores de los libros más importantes de historia y pensamiento político de su tiempo. Ese paradigma del "estadista integral" aún mantenía cierta vigencia en la generación de Perón, y no es de extrañar que él también fuese un autor prolífico y pretendiese sistematizar personalmente la doctrina del justicialismo. Por eso mismo, uno de los aspectos interesantes de "Unidos o Dominados" es que nos permite observar cómo lo práctico se traslada a lo formal.

\section{El código geopolítico peroniano}

Todo actor internacional posee un código geopolítico, que consiste en un conjunto de cálculos (sus alianzas y amenazas, y sus estrategias y argumentos para lidiar con ellas) que definen su orientación al mundo (Flint, 2016, pp.52-54). Esta idea, como admite su autor, es "engañosamente simple", porque la interpretación académica de estos cálculos y justificaciones es un "ejercicio hermenéutico complejo": los análisis suelen realizarse desde la perspectiva de un determinado actor -usualmente, nacional- pero los códigos tienen una naturaleza relacional, con consecuencias no intencionadas sobre otros actores (Flint y Zhu, 2019, p.96). A su vez, otro ejercicio

3 Ver Cohen, (2009). 
hermenéutico complejo es distinguir entre un código y una visión geopolítica, siendo ésta última una noción más amplia que incluye identidades, sentimientos y creencias sobre la misión en el mundo de un determinado actor, que no necesariamente son dominantes ni llegan a traducirse en estrategias o códigos (Dijkink, 1996, pp.11-12); el código geopolítico son las decisiones políticas que intentan realizar la visión geopolítica (Flint y Zhu, ibid.).

Siguiendo algunos de los principales trabajos sobre el periodo (Lanús, 1984; Cafiero, 1996; Escudé y Cisneros, 1999) podemos destacar tres grandes elementos en la orientación al mundo de la Argentina de Perón: la tercera posición en la escala global, el integracionismo en el plano regional, y la reafirmación territorial del Estado argentino en el espacio nacional/local $-\mathrm{y}$ su exterior cercano, que son los países limítrofes- . Ahora bien, estos tres elementos, ¿fueron visiones o códigos geopolíticos? La noción de tercera posición fue presentada por él en 1946 como una doctrina que rechazaba la división del mundo en los dos bloques ideológicos antagónicos emergentes de la posguerra. Sin embargo, Escudé y Cisneros la inscriben dentro de una tradición de larga data, aislacionista y de confrontación diplomática con Estados Unidos y las potencias en general, cuyo inicio ubican en la Conferencia Panamericana de 1889. Tanto Lanús como Cafiero, por su parte, sostienen que el tercerismo no era neutral ni equidistante, sino alternativo y "superador" de los dos bloques ideológicos entonces dominantes. Aunque ninguno de estos autores utiliza el concepto de código geopolítico, podríamos interpretar que para Escudé y Cisneros la tercera posición sería una forma más de un código geopolítico de larga duración, emanado de la visión geopolítica de protagonismo internacional y autonomía respecto de Washington que se originó en tiempos de la Argentina rica de fines del siglo XIX, y que recién lograría ser revisada una vez que el país abrazase el "realismo periférico" (Escudé, 2009), cosa que ocurriría en la década de 1990. En cambio, para Lanús y Cafiero el tercerismo fue un código de corta duración, con posibles antecedentes y legados ${ }^{4}$, pero que no podemos entender sin el marco de la Guerra Fría.

Aunque la tesis de Escudé y Cisneros es desafiante, porque se sustenta en una observación continua de actitudes (o pretensiones) autonomistas a lo largo de la historia de la política exterior argentina, la de Lanús y Cafiero es más atenta al contexto histórico y a los argumentos esgrimidos por el propio Perón, además de más compatible con la historia de la geopolítica moderna propuesta por Agnew (2005), para quien la emergencia de la era geopolítica ideológica en 1945 implicó, en mayor o menor medida, la reconfiguración de todos los códigos geopolíticos nacionales.

La Guerra Fría tiene, para el presidente argentino, un peso ineludible. En La comunidad organizada (Perón, 2016), sin embargo, presenta a la tercera posición como una "idea sociológica de base filosófica", aplicable a todo tiempo y espacio, denominada justicialismo, que es una "doctrina argentina" de aspiración universal, y que sirve de guía ideológica tanto para la política interna ${ }^{5}$ como internacional.

4 Por ejemplo, Lanús señala que un antecedente de la tercera posición fue la "neutralidad" del presidente Hipólito Yrigoyen (Lanús, 1984, p.76).

5 Cabe recordar que en las dos ideologías políticas que el tercerismo proponía superar (capitalismo liberal y comunismo) eran identificables con los partidos conservadores, liberales y de izquierda que habían integrado la Unión Democrática de 1946 y que se mantuvieron como férreos opositores a Perón durante todo su manda- 
Sus lineamientos son el rechazo del capitalismo liberal (individualismo) y del comunismo (colectivismo) como "dos formas del materialismo", y la reivindicación de los valores del humanismo, el pacifismo y el comunitarismo. En la escala internacional, el tercerismo funcionó como una justificación de las posiciones diferenciadas de la Argentina frente a Estados Unidos en temas como el Tratado Interamericano de Asistencia Recíproca (1947) o la crisis de Guatemala (1954), y frente a Estados Unidos y la Unión Soviética en los casos de la independencia de Indonesia, la división de Palestina, la guerra de Corea y otros. Para Lanús (1984, p.80), la tercera posición era una ideología política y no una doctrina diplomática, a pesar de que se presentaba como un compendio general de principios universalizables ${ }^{6}$; la aplicación del tercerismo era dinámica y estaba en función de la diferenciación defensiva respecto de los "dos imperialismos", de cuyos movimientos se desconfiaba a priori porque escondían, invariablemente, estrategias de dominación.

El problema es que la geopolítica ideológica no proveía, en ese entonces, las condiciones materiales para el desarrollo de una ideología alternativa, y que la Argentina carecía de los medios para propagarla. Los dos antiguos aliados durante la guerra contra Hitler, ahora convertidos en superpotencias políticas y militares, se dividieron en torno a cómo organizar Europa - y el mundo- en la posguerra, rivalizando de las más distintas formas; el Tercer Mundo y el Movimiento de los Países No Alineados, que la tercera posición justicialista en cierta forma anticipó, fueron subproductos de la gran confrontación, y tuvieron al menos dos acepciones: pudieron ser la resistencia a la geografía binaria, o el espacio residual de aquellos países que, por diferentes motivos, no se habían decantado aún por uno de los dos modelos de modernización disponibles (Agnew, 2005, capítulo 5.4) ${ }^{7}$. En cualquiera de las dos, la alternativa era una categoría que tomaba a las otras dos como referencia, y era parte de la dialéctica de la Guerra Fría. La aspiración universal — aunque Perón (2020, p.178) aclara que su ideal no se proponía objetivos "extracontinentales"- de la tercera posición y su carácter relacional se realizaban en la medida que ésta fuera adoptada por más países sudamericanos, y que ellos coordinasen sus políticas frente a las imposiciones — potencialmente bélicas, como ya podía verse en Corea- del antagonismo entre Estados Unidos y la Unión Soviética. En perspectiva, hoy la tercera posición se nos muestra como una visión geopolítica peroniana para la Argentina y la región, motivada en el interés de contener la influencia de Estados Unidos en Sudamérica — que se venía incrementando con la dinámica arrolladora de la geopolítica de la Guerra Fría, que tanto el presidente argentino

to. Eso permite entender por qué la tercera posición no era equidistante sino alternativa a las ideologías de la Guerra Fría: Perón antagonizaba con ellas en la política interna argentina.

6 Estos serían: “a) la igualdad jurídica de todos los Estados soberanos; b) la fraternidad y cooperación política y económica, como única forma de aproximar a las naciones sin recelo; c) la amistad con todos los países del mundo, sin inclinarse hacia las hegemonías de izquierda y derecha; d) la voluntad de servir a la humanidad en sus anhelos de paz interna e internacional, colocándose en la línea de ayuda 'que le sugería el clamor universal' y sirviendo a 'las energías del bien, para vencer las energías dominadas por el mal'; y e) la situación de los pueblos en el concierto general, donde debían extender sus conceptos nacionales” (Escudé y Cisneros, 1999, capítulo 61, conclusión).

7 Hay que destacar que, según Lanús, la adhesión al Movimiento de Países No Alineados por parte de un país no necesariamente implicaba la adopción de los principios de la tercera posición. En general, la literatura destaca que el bloque de No Alineados ha sido heterogéneo, que sus posiciones han ido cambiando a lo largo de la Guerra Fría y que el denominador común, antes que una doctrina estable, era la "solidaridad basada en intereses y problemas comunes" (Pérez Llana, 1973, p.65). 
como el brasileño la habían sufrido-, que enfatizaba su anticomunismo y su alineamiento con los valores occidentales para no aparecer como una alternativa esencialmente anti-Washington. De hecho, la política exterior de Perón buscaba entendimientos con los Estados Unidos, sobre todo a partir de 1952. Sin embargo, su visión encontró fuertes límites - endógenos y relacionales - cuando quiso convertirse en un código geopolítico argentino o regional. No logró, por ejemplo, que otros gobiernos de la región la adoptasen como posición ante la Guerra Fría. Hubo casos de dirigentes políticos de otros países de Sudamérica que se definían como justicialistas y terceristas ${ }^{8}, \mathrm{y}$ probablemente el argentino pretendía que la tercera posición fuese un código común de los líderes nacional-populares de la región (Ibañez del Campo en Chile, Paz Estenssoro en Bolivia, Velasco Ibarra en Ecuador, Vargas en Brasil). También es probable que el Departamento de Estado norteamericano estuviese preocupado por la posibilidad de un bloque tercerista en América del Sur a comienzos de los 1950 (Zanatta, 2013; Darnton, 2014). Pero lo cierto es que dicha alternativa no llegó a constituirse como tal.

La política de integración regional de Perón, en cambio, sí constituye un código geopolítico más operativo y menos dependiente de las coyunturas. Surge de la misma visión geopolítica que la tercera posición: reducir la influencia de Estados Unidos en la región sudamericana, que era el "espacio de solidaridad política y complementación económica", y maximizar a partir de esa contención las posibilidades geopolíticas de la Argentina. Pero en este caso, a diferencia de la anterior, la conversión de la visión a código — un código propio - permite una selección de aliados permanentes, estrategias persistentes, y cursos de acción (políticas) diversos para aproximarse al objetivo. En "Unidos o Dominados", Perón expone su visión de largo plazo: Sudamérica es una región rica (en recursos naturales), esa riqueza será codiciada por potencias extrarregionales, y los Estados-nación que la constituyen, por separado, carecen de la fuerza suficiente para evitar la dominación económica a la que luce condenada. Por eso, la estrategia óptima para enfrentar ese destino es la unión económica, que es la fórmula que utiliza para definir a una unión aduanera ${ }^{9}$ con coordinación de políticas externas $-\mathrm{y}$ militares - por parte de los socios; uno de sus objetivos era evitar el deterioro de los precios de intercambio de los productos agroalimentarios y otras materias primas, en relación con los productos manufacturados, que iba a afectar por igual a los tres países incluidos en el proyecto ABC (Moniz Bandeira, 2010, pp.239-40). Para concretarla, el primer paso es modificar el "aislacionismo", actitud que dentro de la región atribuye, en la historia, fundamentalmente a la política exterior argentina, y su visión de la insularidad —el planteo del almirante Storni (1952)—y excepcionalidad nacional

8 Como el caso de María De la Cruz Toledo, primera senadora de la historia de Chile y líder del Partido Femenino, ibañista, que en sus intervenciones en el Senado de su país se definía como justicialista y alineada con la tercera posición peronista. Decía, por ejemplo, en 1953: "Y así como hablé entonces, porque tuve fe en un hombre, tuve fe en un cambio favorable para los proletarios de la Patria, tuve fe en un seguro resurgimiento de la Patria para beneficio de todos, así también hablé, con la misma fe, cuando defendí mis sentimientos justicialistas: con la fe que me inspira una doctrina que señala una tercera posición entre los extremos del sistema capitalista liberal y del sistema marxista del socialismo de Estado". Ver Diario de Sesiones del Senado, Sesión 15 va., 29 de julio de 1953, p. 723.

9 La idea de unión aduanera sudamericana aparece previamente en varias intervenciones de Perón, incluida una entrevista con el diario O Mundo de Brasil en enero de 1948 (citada por Lanús, 1984, p.285). 
dentro del continente. Pero ahora, en 1953, el problema del aislacionismo estará en Brasil.

Nótese que, a partir de la adopción de un código geopolítico regionalista, el problema del aislacionismo se resignifica. Al igual que los partidarios de la alianza primaria con las potencias occidentales, Perón afirma que la tendencia al aislacionismo impide la realización de los intereses nacionales argentinos. Pero para él, aislacionismo es otra cosa: no es el aislamiento respecto de la escala mundial/global, sino de la regional. En efecto, su primera presidencia empezó con problemas en el primer orden: los Estados Unidos y la Unión Soviética ya habían "castigado" a la Argentina y otros países de bajo compromiso con los aliados en la Segunda Guerra, no invitándola al primer grupo de integrantes de la Organización de las Naciones Unidas. Perón, bajo el seudónimo de Descartes (1953), escribirá entre 1951 y 1952 diferentes columnas de opinión con fuertes críticas al nuevo sistema internacional basado en la ONU, al que verá como un mero instrumento de los intereses mundiales de estadounidenses y soviéticos. La principal tensión con el sistema internacional no provendrá del "castigo" de las potencias a la Argentina, sellado en Yalta (febrero de 1945, cuando Perón aún no era presidente) sino de las políticas terceristas a partir de 1946, ya que la Argentina se negó a participar del nuevo multilateralismo y se mantuvo alejada del FMI, el Banco Mundial y las reuniones del GATT (Lanús, 1984, pp.49-50); asimismo, la diplomacia peronista llevaba posturas diferenciadas a las de Estados Unidos en la mayoría de las reuniones del sistema interamericano (Cafiero, 1996, pp.42-52). Sin embargo, para Perón el aislacionismo era negar el destino continental de la Argentina. Contradiciendo la tesis de Escudé $(1999 ; 2009)$ sobre la voluntad de poder de una Argentina que no pondera adecuadamente lo insuficiente de sus capacidades, o de Zanatta (2013) sobre la vocación "imperialista" (a nivel regional) del justicialismo — basada en el hecho, probado, de que en Chile, Uruguay y Brasil había muchos desconfiados de Perón y las motivaciones de su regionalismo-, la narrativa del código regionalista peroniano no demuestra pretensiones de grandeza. La actitud del unionismo, o integracionismo, se basa en el reconocimiento del carácter de "país pequeño" de la Argentina, y de sus límites para enfrentar las estrategias de las potencias mundiales dominantes; la debilidad es la circunstancia "que ha inducido a nuestro gobierno a encarar de frente la posibilidad de una unión real y efectiva de nuestros países" (Perón, 2020, p.176).

El código geopolítico integracionista aparece definido, también, por el hecho de que la política exterior argentina acudió al bilateralismo con los países sudamericanos, con los mismos objetivos de contener a Estados Unidos y mejorar la posición argentina en su espacio regional. Desde 1946, Argentina suscribió convenios y acuerdos con sus vecinos, pero entre 1953 y 1954 firmó acuerdos de complementación y unión económica con cinco países de la región (Cafiero, 1996, p.55). Tras el fracaso del $A B C$, el impulso a la firma de tratados se aceleró, lo que fue presentado como una alternativa al "multilateralismo globalista" (ibídem.), y, eventualmente, como una vía para destrabar la frustración del proyecto del $A B C$ : "quizá al hacerse esto se facilite la acción de Vargas" (Perón, 2020, p.181). En suma, el código geopolítico argentino era la integración y la solidaridad sudamericana, y las diferentes políticas que fue ensayando $(A B C$, tratados bilaterales, afinidad entre presidentes 
nacional-populares) fueron las alianzas y estrategias que lo componen. Su persistencia a lo largo del tiempo nos demuestra la sustancialidad del código.

Finalmente, el tercer elemento de la orientación al mundo de Perón antes señalado, que fue la reafirmación geopolítica ${ }^{10}$ del Estado argentino, también incluyó alianzas y estrategias claramente discernibles, y se inscribe en una historia de larga duración. El presidente se concibe a sí mismo como un gobernante que viene a completar la tarea inconclusa de la construcción del Estado argentino, y para eso no solo refunda el Estado sobre la base de un nuevo contrato social, sino que implementa una serie de políticas para asegurar la soberanía territorial. Era un pacifista, tal como demuestran tres decisiones constitutivas de su biografía política: su doctrina tercerista - contraria a la Guerra Fría y a la hipótesis de una nueva guerra mundial—, su política de solidaridad regional y eliminación de las hipótesis de conflicto en el exterior cercano, y su renuencia a luchar en los conflictos políticos internos que lo involucraron (su encarcelamiento en 1945, su derrocamiento en 1955, y su violento retorno del exilio en 1972 y 1973). No obstante, Perón promovió el equipamiento militar argentino, la implementación de los acuerdos fronterizos con Chile y Paraguay, la incorporación de los "territorios nacionales"" a la vida cívica argentina, la politización de los reclamos por Malvinas, la Antártida y las islas del Atlántico Sur. E incorporó a la retórica presidencial una dimensión nacionalista-popular y soberanista, que impregnó al movimiento peronista. Su conocido lema "primero la patria, luego el movimiento y después los hombres" se reconvirtió en un sencillo orden de prelación para definir el sentido de la política exterior: "primero la República Argentina, luego el continente y después el mundo" (Perón, 2020 , p.178). Esta noción de la primacía de lo nacional, habitual en la fundamentación de las políticas exteriores de los Estados-nación, aparece siempre en la enunciación de las visiones geopolíticas y del código geopolítico de Perón. La solidaridad política con el exterior cercano, la conciencia del Atlántico Sur antártico, la unión o integración regional y la tercera posición, todas giran en torno de la defensa de la soberanía, la integridad territorial y los intereses del Estado argentino. Esta visión es el núcleo de su código geopolítico, y de las políticas externas derivadas de él, y no lo aleja demasiado de la noción estadocéntrica convencional. La innovación de Perón residirá en su concepción acerca de la dimensión social de la espacialización regional y, eventualmente, global.

\section{Discusión: ¿código geopolítico nacional o nacionalismo latinoamericano?}

El hecho de que la visión geopolítica de Perón haya combinado ideas convencionales sobre el Estado-nación e innovadoras en lo que hace a la relación de ese Estado

10 Así definen Yves Lacoste y su escuela a las políticas nacionales tendentes a asegurar la integridad territorial. Ver Gourdin (2010, p.20) y Tellenne (2019, p.30).

11 Los territorios nacionales eran un conjunto de jurisdicciones de la Patagonia y el nordeste argentino, que habían sido incorporadas tardíamente al estado nacional y no tenían la misma entidad política que las provincias históricas de la federación. En principio, no elegían a sus propias autoridades ni tenían representación en el Congreso, y estaban bajo control directo del estado federal. Para mediados del siglo XX, estos territorios -que representaban más de la mitad de la superficie de la Argentina continental- aún conservaban este estatus provisorio. Perón impulsó la transformación de los territorios en provincias, lo que implicó la ciudadanía política para sus habitantes. 
con su entorno, nos remite a una de las preguntas iniciales: ¿cuál es el lugar epistemológico de la geopolítica peroniana? Nuestro argumento es que el General, desde la práctica y la conceptualización, fue un precursor en Sudamérica de lo que más avanzado el siglo XX se denominará geopolítica crítica. Dodds (2000), abonando en esa dirección, sostiene que Perón representó una ruptura con el pensamiento geopolítico clásico, que ya tenía expresión en Argentina desde principios del siglo XX — comenzando con el trabajo de Storni, que fue publicado por primera vez en 1916, pero también a través de influencias indirectas - y que luego retornaría con las dictaduras militares postperonistas de los 1960 y 1970 . Que harán una funesta relectura de los autores europeos fundacionales de la geopolítica europea, en un contexto de la Guerra Fría e inestabilidad política interna, y utilizarán sus nociones geográfico-políticas para justificar el terrorismo de Estado y el belicismo intrarregional; Dodds, en cambio, ubica a Perón y su era de pacifismo tercerista y regionalista como una suerte de paréntesis entre dos geopolíticas militaristas.

Sin embargo, en los últimos años se ha extendido en Sudamérica la idea de que Perón estaba influido por la geopolítica clásica, particularmente por Ratzel, naturalista alemán devenido geógrafo, que fue uno de los fundadores de la escuela alemana de geopolítica (López Trigal, 2011). Y que esa influencia ratzeliana fue determinante en su visión regionalista. Quien acuñó esa idea fue Alberto Methol Ferré, pensador uruguayo influyente en ámbitos académicos y políticos, quien en diferentes obras destacó la vigencia de Ratzel y buscó hermanarlo con Perón, a cuyas iniciativas regionalistas suscribía con entusiasmo. El nexo que Methol encuentra entre Ratzel y Perón es el concepto de continentalismo, que ambos utilizaron; Ratzel, fascinado en sus primeros trabajos geográficos por Estados Unidos y su evolución económica y espacial, encontró en el "Estado-continente" norteamericano un modelo para la Alemania del siglo XX; Perón, por su parte, en sus reiteradas referencias al continente y al destino continental de la humanidad, encontró en esta construcción geográfica naturalizada pero imprecisa (¿qué es un continente?) una forma para visualizar su modelo de unión regional, y legitimarla en lo que bien podría ser una tendencia mundial entonces observable (las federaciones estadounidense, soviética y, próximamente, europea).

Es evidente que trazar una línea directa entre la geopolítica clásica ratzeliana y Perón tuvo importancia para Methol y sus discípulos, ya que se empeñaron en buscarla. Pero el problema es que Perón nunca citó a Ratzel, no se encontraron sus obras en su biblioteca, y en las muy escasas referencias al término geopolítica que hizo en su vida — una de ellas, en "Unidos o Dominados"-, el General toma distancia de sus acepciones clásicas. El nexo está basado en una inferencia que va tomando forma de convicción. Refiriéndose al artículo "Conferencias continentales", que Perón publica (bajo el seudónimo de Descartes) el 20 de diciembre de 1951 (Perón, 1953), dice Methol Ferré (2009) que "tiene olor a Ratzel, pero jamás se dijo ni se supo" (p.113). Barrios, por su parte, afirma que "la escuela geopolítica de Ratzel tuvo una influencia excepcional en la escuela prusiana, de la cual hay que distinguir al futuro subteniente Juan Perón, quien egresa en 1913 como integrante de la primera promoción del Colegio Militar que estudia sobre la base de los planes del modelo prusiano" (Barrios, 2008, p.62), y a partir de allí deriva que "Ratzel tuvo una marcante influencia sobre Perón" (ibid., p.164) y que "sin duda, Perón adquiere y recibe la influencia de Ratzel en lo que hace a la idea fuerza de la marcha 
evolutiva en el sentido virtual y político del continentalismo-universalismo, que aplica a la realidad de América del Sur" (ibid., p.166). Continúa preguntándose si acaso Perón hace una traslación mecánica de "las lecturas de Ratzel" (sic) al contexto argentino/latinoamericano, y responde que, en realidad, lo que hace el general es una adaptación con la tradición latinoamericanista (Ugarte, Rodó, García Calderón). Sobre esto, Methol Ferré afirma categóricamente que "Perón junta la línea histórica latinoamericana con el pensamiento geopolítico alemán" (citado en Barrios, 2008, p.167). Este supuesto de Methol Ferré y Barrios, según el cual Perón leyó a Ratzel y esa lectura influyó en su pensamiento y práctica geopolítica, fue tomado como dado por otros autores, que continuaron elaborando sobre la noción de un Perón ratzeliano; podemos seguir el rastro de esta idea en Perrotta y Martínez Larrechea (2019) ${ }^{12}$, Jaguaribe, Rivarola y Calduch $(2017)^{13}$, Rivarola Puntigliano $(2013 ; 2017)^{14}$ o Podetti (2009).

Cabe destacar que Ratzel es más conocido por su comprensión organicista del Estado, por haber introducido el concepto de lebensraum (espacio vital), y por su apoyo al pangermanismo, que por sus reflexiones acerca del Estado-continente norteamericano, que fueron sus trabajos de juventud. Se sostiene que el uso que su "discípulo" Haushofer y los nazis hicieron del concepto de lebensraum pudo haber sido una tergiversación del ratzeliano (Cairo, 2011, p.341), y hay una suerte de consenso entre los académicos actuales acerca de la dificultad de cargar a Ratzel, fallecido en 1904, con la responsabilidad intelectual de lo que los nazis hicieron con su obra (Encel, 2011, p.40). Sin embargo, la pregunta es pertinente: ¿por qué acudir a Ratzel, un zoólogo darwinista anclado en la ciencia del siglo XIX, inmerso en la realidad alemana de su época, y creador de una batería de conceptos superados que han suscitado fuertes controversias, para entender a Perón, un argentino del siglo XX obsesionado con romper con las categorías clásicas, y repensarlas desde el "nuevo mundo" del sur?

Una respuesta posible es la de Methol Ferré, en tanto autor original que desarrollaba un pensamiento propio abrevando en diferentes fuentes, no era en sí mismo un ratzeliano —su influencia principal fue Felipe Herrera (Hernández Nilson, 2020, p.8) - sino más bien alguien que encontró en Ratzel "una argumentación geopolítica que le resultó funcional" (Podetti, 2009, p.83). El objetivo de Methol Ferré era reconstruir una tradición del pensamiento latinoamericano, trazando para ello lazos vinculantes entre autores de diferentes épocas y nacionalidades - a quienes Perón, como en el caso de Ratzel, tampoco citaba-, y extrayendo un denominador común cultural; su perspectiva es una "geopolítica de la cultura", derivando de ella las implicaciones políticas, e inspirada en una visión católica de la "nación

12 "Juan Domingo Perón y Alberto Methol Ferré han construido su pensamiento y su praxis política a partir de las ideas de la geopolítica de inicios del siglo XX, que destaca especialmente la cuestión de la continentalidad" (Perrotta y Martínez Larrechea, 2019, p.132).

13 “Juan Domingo Perón es el máximo totalizador de la geopolítica latinoamericana. Para Perón, la unidad empieza por la conjunción argentino-brasileña en el macizo subcontinental, es decir, desde la unidad sudamericana hacia la unidad latinoamericana, a partir de la equipolaridad hispano-lusitana de América del Sur. Heredero de la tradición latinoamericana de Manuel Ugarte -quien fuera su embajador- y de la geopolítica de Friedrich Ratzel, proclama la formación del Estado continental como única posibilidad de escapar de la dominación a partir de la unión." (Jaguaribe, Rivarola y Calduch, 2017, p.277).

14 "Perón's geographical consciousness was more than intuitive, since he graduated in 1913 from military school, where he learned geopolitics. One can see in his worldview a strong influence from Ratzel, Jean Monnet and other European thinkers" (Rivarola Puntigliano, 2013, p.35). 
latinoamericana", de orígenes históricos y con componentes identitarios y hasta "etnopolíticos" (Rivarola Puntigliano, 2013, p.27); Methol se propuso algo novedoso, que fue una "geopolítica latinoamericana, y no de orientación nacional" (Podetti, 2009, p.86). Pero al mismo tiempo, necesitaba unir esa nación cultural imaginada con una noción geopolítica y allí es donde aparece la funcionalidad de los escritos de Ratzel, quien no solo es un pensador de la continentalidad sino, también, de la aglutinación pangermánica de las "pequeñas nacionalidades" en una identidad nacional mayor. Más que la Unión Europea de finales del siglo XX, para Methol Ferré el modelo para Sudamérica/Latinoamérica se asemejaba más al Zollverein alemán de 1834 (Methol Ferré, 2009, p.79), la unión aduanera que fue el inicio de la unificación alemana bajo una misma nacionalidad. Entonces, las referencias a Ratzel y a Friedrich List adquieren otro sentido. Un Perón que aparece como el único vértice capaz de sintetizar la geopolítica clásica y el latinoamericanismo cultural, y que intentó poner todo eso en marcha desde el ejercicio de un liderazgo popular que trascendió las fronteras, cuyo nombre permanece vigente a pesar de los tiempos, se convirtió en un mito político necesario. El problema es que ese personaje fue, cada vez más, una construcción de Methol Ferré que se alejaba de su contexto y sus motivaciones ${ }^{15}$. Vuelve, otra vez, la disputa por la visión de Perón.

Mientras que el rescate de Ratzel pudo resultar funcional para el pensamiento metholiano, asociar a Perón con Ratzel resulta problemático y disfuncional para la historia del pensamiento geopolítico sudamericano. En la búsqueda de continuidades, se lo termina ubicando en una tradición equivocada. Si el General fue ratzeliano, entonces la geopolítica argentina fue un continuo durante todo el siglo $\mathrm{XX}$. Y los argumentos de los funcionarios de Washington e Itamaraty a comienzos de los años 1950, sobre el supuesto expansionismo peronista, tendrían fundamentos. Esta tesis sobre un Perón clásico y latinoamericanista subestima algunos motivaciones políticas y discursivas evidentes, como su preocupación por la soberanía del Estado argentino y por enfrentar los efectos de la nueva hegemonía, y no indaga en otra agenda posible de investigación histórica: la de la originalidad conceptual de la práctica y el pensamiento geopolítico del sur.

\section{Giro a una geopolítica alternativa: la (geo)estrategia nacional-popular}

Perón utilizó muy pocas veces la palabra geopolítica, al menos en público, a lo largo de su vida. "Unidos o Dominados" es una de ellas. Dice:

La lucha por las zonas amazónicas y del Plata no tiene ningún valor ni ninguna importancia; son sueños un poco ecuatoriales y nada más. No puede haber en ese

15 Otra hipótesis interesante para interpretar al Perón latinoamericanista y ratzeliano de Methol Ferré, es que el autor uruguayo era un pensador de las continuidades y no de las rupturas, idea que desarrolla Hernández Nilson (2020). Por caso, a Methol no le gustaban los análisis que hablaban de diferentes etapas del regionalismo sudamericano/latinoamericano ( $v g$., regionalismo liberal y postliberal), y destacaba la perdurabilidad del proceso histórico. En ese sentido, no sería de extrañar que a Methol le incomodase la idea de que Perón fuera una ruptura con la geopolítica tradicional, y prefiriese enfatizar las continuidades históricas del pensamiento geográfico-político. 
sentido ningún factor geopolítico ni de ninguna otra naturaleza que pueda enfrentar a estas dos zonas tan diversas en todos sus factores y en todas sus características. (Perón, 2020, p.183).

La tesis del antagonismo entre el Amazonas y el Plata a la que hace referencia fue, probablemente, una de las más conocidas de la geopolítica clásica sudamericana. Su autor fue el coronel Mario Travassos (1978), quien, en Proyección continental del Brasil, publicado por primera vez en 1931, sostenía que el continente estaba atravesado por dos dicotomías geográficas: los océanos Atlántico vs. Pacífico, y los ríos Amazonas vs. El Plata. La primera dicotomía lucía entonces saldada, porque la economía atlántica dominaba el comercio exterior sudamericano y las grandes ciudades-puerto (la modernidad) se concentraban allí. La segunda, en cambio, avizoraba una competencia inevitable entre las dos naciones del Atlántico, Brasil y Argentina. Travassos, quien sí estaba influido por Ratzel y Mackinder, y teorizaba acerca de la correcta ubicación del heartland sudamericano, dejó una huella importante en el pensamiento geopolítico brasileño — formal y práctica-, ya que buena parte de sus obsesiones, como la red ferroviaria, la zona franca de Manaos, o la "marcha hacia el oeste" selvático, se hicieron realidad. Perón menciona esa controversia y sin intervenir en ella siquiera, la da por cerrada. La era de la geopolítica clásica terminó; "son sueños". Ahora, la única verdad es la realidad de la conflagración entre Washington y Moscú, y el camino señalado es la unidad defensiva de los pueblos con problemas comunes. Pero el abandono de la geopolítica clásica y el no alineamiento en la Guerra Fría lleva directo a un vacío conceptual. Porque después de la geopolítica clásica, en la década del 1950, no había nada.

Dijkink (2004, p.472) se pregunta por las causas de la inexistencia de una geopolítica crítica (y de toda producción geopolítica) entre los años 1950 y 1970, y establece una comparación con lo que sucede después. Sostiene que las dos principales corrientes académicas de geopolítica crítica surgidas a partir de entonces - la francesa, a partir del trabajo de Yves Lacoste en 1976 sobre el bombardeo de los diques del río Rojo (2011), y la anglosajona desde fines de los 1980 - surgieron como una crítica a los efectos de las nuevas formas de geopolítica territorialista de sus respectivos Estados en regiones como Argelia, Vietnam, Medio Oriente, o Centroamérica. En ambos casos, sostiene el autor, estos enfoques críticos fueron precedidos por climas intelectuales (universitarios) que los hicieron posibles (por ejemplo, mayo de 1968, movimiento pacifista, etc.). Sin embargo, y a pesar de las inquietantes consecuencias posibles de una geopolítica sostenida sobre la amenaza de destrucción mutua asegurada, las primeras décadas de la Guerra Fría "no produjeron ninguna visión alternativa del orden mundial" (Dijkink, ibidem.); solo descripciones de la práctica de las relaciones internacionales. Eso sugiere que una geopolítica crítica de la Guerra Fría fue políticamente inconcebible en las sociedades atravesadas por la confrontación ideológica, pone en perspectiva lo peculiar del experimento tercerista de Perón, y explica su dificultad para convertirse en un código geopolítico en un mundo carente de visiones alternativas. Hay dos elementos a destacar en el presidente argentino de 1953: 1) sus críticas del orden mundial de la Guerra Fría, y 2) su descubrimiento de los límites de la política exterior de los Estados-nación, y su efecto en la concepción de una geopolítica de los pueblos. Luego, el Perón del exilio y los años 1970, con otro tipo de relación respecto de la 
política práctica, incorporará más elementos a considerar (universalismo, antiimperialismo, ecologismo...) (Perón, 2015; 2017). Pero, siguiendo el razonamiento de Dijkink sobre la presunta necesidad de un contexto político-intelectual posibilitante para la formulación de la crítica geopolítica, podemos decir que el Perón antiimperialista y crítico de la Guerra Fría de fines de los años 1960 y principios de los 1970 ya estaba bajo el amparo de los diversos discursos críticos que habían aparecido en diferentes partes del mundo; el de principios de los 1950, en cambio, predicaba en una relativa soledad:

1. Sobre el orden mundial, una escala lejana y opaca en el contexto de la primera posguerra, Perón se expresa en columnas de opinión semanales publicadas en el diario Democracia bajo el seudónimo Descartes (Perón, 1953). Allí hace diversos tipos de declaraciones. Puede opinar como un observador: "Los pueblos del mundo, cansados de luchar, solo anhelan vivir en paz con lo que tienen. La humanidad estaría mejor gobernada por sus pueblos. El justicialismo es perseguido porque cuestiona el belicismo de los personeros de los pueblos" (22 de febrero de 1951). O hacer gala de un idealismo con rasgos utópicos: "El justicialismo, constructivo y ecuánime, desterrará de la humanidad la explotación del individuo por el Estado, como también la del hombre por el dinero" (31 de mayo de 1951). O acusar a todos los actores por igual: "Los Estados Unidos, la Unión Soviética y las Naciones Unidas preparan la guerra con el pretexto de la paz" (15 de febrero de 1951). En cambio, desde el discurso como jefe de Estado no puede soslayar sus restricciones para formular una alternativa. Pero consciente de la restricción, defiende la existencia de un marco para el ejercicio de las ideas: "Dentro de esa situación podemos tener nuestras ideas y luchar por ellas para que las cancillerías, que juegan al estilo del siglo XVIII, no nos estén dominando con sus sueños fantásticos de hegemonía, de mando y de dirección" (Perón, 2020, p.178). La perspectiva crítica, en el contexto asfixiante del orden mundial de los años 1950, consistirá en evitar la dominación.

2. La geopolítica crítica contemporánea surge, en buena medida, al calor del rol que tuvieron los movimientos sociales en la transformación geográficopolítica de Europa a fines del siglo XX (Miller, 2000). Los cambios en el mapa de Europa central y oriental tras el simbólico nodo inicial de "la caída del Muro de Berlín" estuvieron caracterizados, al menos inicialmente, por la actuación de movimientos identificados con una nueva sociedad civil. Y esto produjo una conciencia acerca del peso (geo)político de los actores sociales no estatales. Este descubrimiento también lo hace Perón, cuarenta años antes y desde otro lugar. En "Unidos o Dominados" podemos ver su frustración porque el límite a su más importante iniciativa geopolítica provino del canciller brasileño, Neves de Fontoura, y más concretamente, de Itamaraty, la sede de la diplomacia brasileña, a la que Perón se refiere como un poder independiente del gobierno y a la que apunta como principal problema para la unión regional (Perón, 2020, p.180). Cuenta como su par brasileño, Vargas, le explica a través de un emisario que él no controla a su canciller. Aunque también agrega que un mejor entendimien- 
to de su parte con Estados Unidos “puede ayudar". Perón y Vargas eran los presidentes más votados de la historia de sus respectivos países, pero eso no resultó suficiente. Por eso, concluye que lo más efectivo es influir "sobre los pueblos (...) porque los hombres pasan y los gobiernos se suceden, pero los pueblos quedan" (ibid., p.177). Un cambio profundo debe contar con apoyo popular. Y agrega, de paso, que el pueblo argentino sí está listo para aceptar una transformación en la orientación al mundo - sugerida por Perón, desde luego- porque ya posee una "conciencia políticointernacional" (ibid., p.180).

Siguiendo ese razonamiento, el proyecto $A B C$ fracasó, según el presidente argentino, porque los pueblos de los tres países no contaban en ese momento con el mismo nivel de conciencia político-internacional. Los términos del análisis se invierten: no fue el peso de Itamaraty, ni las eventuales presiones de Estados Unidos, las que pusieron un freno al regionalismo, sino una insuficiente conciencia popular que permitió que esos factores operen con eficacia. Por eso, insiste en que la guerra de la integración no está perdida; solo se ha perdido una batalla. La estrategia nacional-popular para la consolidación de una conciencia pacifista y regionalista será de largo plazo, y dependerá de que amplias mayorías la respalden. De hecho, la paz regional y el regionalismo, a pesar de sus desempeños dispares, son desde hace décadas valores indisputados en Sudamérica.

\section{Referencias}

Agnew, J. (2005). Geopolítica: una re-visión de la política mundial. Madrid: Editorial Trama.

Barrios, M. (2008). Perón y el peronismo en el sistema-mundo del siglo XXI. Buenos Aires: Editorial Biblos.

Cafiero, A. (1996). La política exterior peronista 1946-1955. El mito aislacionista. Buenos Aires: Editorial Corregidor.

Cairo, H. (2011). La Geopolítica como "ciencia del Estado": el mundo del general Haushofer. Geopolítica(s). Revista de estudios sobre espacio y poder, 3(2), 337-345.

Cohen, P. (2009). Just How Relevant Is Political Science? The New York Times, 19 de octubre. Recuperado de https://www.nytimes.com/2009/10/20/books/20poli.html

Darnton, C. (2014). Rivalry and Alliance Politics in Cold War Latin America. Baltimore: Johns Hopkins University Press.

Dijkink, G. (1996). National Identity and Geopolitical Visions: Maps of Pride and Pain. London: Routledge.

Dijkink, G. (2004). Geopolitics as a Social Movement? Geopolitics, 9(2), 460- 475.

Dodds, K. (2000). Geopolitics and the geographical imagination of Argentina. En K. Dodds y D. Atkinson (Eds.), Geopolitical Traditions: A century of geopolitical thought (pp.150-184). London: Routledge.

Encel, F. (2009). Comprendre la géopolitique. Paris: Éditions du Seuil.

Escude, C. (2009). Peripheral Realism: An Argentine Theory-Building Experience, 19861997. En J. F.Sombra Saraiva (Comp.), Concepts, Histories and Theories of International Relations for the 21st Century: Regional and National Approaches (pp.223-247). Brasilia: IBRI. 
Escudé, C., y Cisneros, A. (1999). Capítulo 61: La tercera posición en la era peronista. En Escudé, C.; Cisneros, A., Historia general de las relaciones exteriores de la República Argentina, versión online. Recuperado de: http://www.argentina-rree.com/13/13010.htm

Flint, C. (2016). Introduction to Geopolitics. London: Routledge.

Flint, C., y Zhu, C. (2019). The geopolitics of connectivity, cooperation, and hegemonic competition: The Belt and Road Initiative. Geoforum, 99(1), 95-101.

Gourdin, P. (2010). Géopolitiques: Manuel pratique. Paris: Éditions Choiseul.

Hernández Nilson, D. (2020). La experiencia nacional-popular en el pensamiento de Alberto Methol Ferré sobre la integración regional latinoamericana. Iberoamericana - Nordic Journal of Latin American and Caribbean Studies, 49(1), 1-11.

Jaguaribe, H., Rivarola, A., y Calduch, R. (2017). La geopolítica. En H. Sánchez de la Barquera y Arroyo (Ed.), Antologías para el estudio y la enseñanza de la ciencia política. Volumen II: Régimen político, sociedad civil y política internacional (pp.273280). México: UNAM, Instituto de Investigaciones Jurídicas.

Lacoste, Y. (2011). Investigación sobre el bombardeo de los diques del río Rojo (Vietnam, verano de 1972). Método de análisis y reflexiones de conjunto. Geopolítica(s). Revista de estudios sobre espacio y poder, 2(2), 313-337.

Lanús, J. A. (1984). De Chapultepec al Beagle. Política exterior argentina 1945-1980. Buenos Aires: EMECÉ.

López Trigal, L. (2011). Comentario: "Las leyes del crecimiento espacial de los Estados" en el contexto del determinismo geográfico ratzeliano. Geopolítica(s). Revista de estudios sobre espacio y poder, 2(1), 157-163.

Methol Ferré, A. (2009). Los estados continentales y el MERCOSUR. Merlo: Instituto Superior Arturo Jauretche / SADOP.

Miller, B. (2000). Geography and Social Movements: Comparing Antinuclear Activism in the Boston Area. Minneapolis, MN: University of Minnesota Press.

Moniz Bandeira, L. A. (2010). Brasil, Argentina e Estados Unidos. Conflito e integração na América do Sul. Rio de Janeiro: Editora Civilização Brasileira.

Ó Tuathail, G. (1996). Critical geopolitics: the politics of writing global space. London: Routledge.

Pérez Llana, C. (1973). América latina y los países no alineados. Estudios Internacionales, 6(24), 43-65.

Perón, J. D. (bajo el seudónimo Descartes). (1953). Política y estrategia. No ataco, critico. Buenos Aires: s/e.

Perón, J. D. (2015). Modelo argentino para el proyecto nacional. Buenos Aires: Editorial Biblioteca del Congreso de la Nación (Colección: JDP: los trabajos y los días).

Perón, J. D. (2016). La comunidad organizada. Buenos Aires: Editorial Biblioteca del Congreso de la Nación (Colección: JDP: los trabajos y los días).

Perón, J. D. (2017). La hora de los pueblos. Latinoamérica: ahora o nunca. Buenos Aires: Editorial Biblioteca del Congreso de la Nación (Colección: JDP: los trabajos y los días).

Perón, J. D. (2020). Unidos o Dominados (Discurso pronunciado el 11 de noviembre de 1953 en la Escuela Nacional de Guerra). Geopolitica(s). Revista de estudios sobre espacio y poder, 11(1), 173-183.

Perrotta, D., y Martínez Larrechea, E. (2019). El Estado Continental y la geopolítica de la integración: de Juan Domingo Perón a Alberto Methol Ferré. Iberoamericana - Nordic Journal of Latin American and Caribbean Studies, 48(1), 132-145.

Podetti, J. R. (2009). Alberto Methol Ferré y la geopolítica sudamericana. Cuadernos del CLAEH, 32(2), 81-87. 
Rivarola Puntigliano, A. (2013). Geopolitics and Integration: a South American Perspective. En A. Rivarola Puntigliano y J. Briceño Ruiz (Eds.), Resilience of Regionalism in Latin America and the Caribbean. Development and Autonomy (pp.19-52). London: Palgrave Macmillan.

Rivarola Puntigliano, A. (2017). América Latina y el nacionalismo continentalista. Cuadernos sobre Relaciones Internacionales, Regionalismo y Desarrollo, 12(23), 5388.

Storni, S. (1952). Intereses argentinos en el mar. Buenos Aires: Instituto de Publicaciones Navales.

Tellenne, C. (2019). Introduction à la géopolitique. Paris: PUF.

Travassos, M. (1978). Proyección continental del Brasil. Buenos Aires: El Cid Editor.

Zanatta, L. (2013). La Internacional Justicialista. Auge y ocaso de los sueños imperiales de Perón. Buenos Aires: Editorial Sudamericana. 